\title{
Impact of Ultraviolet Photography on Sun Safety Practices of Snow Sport Industry Conference Attendees
}

\author{
Trevor Jones ${ }^{1,2}$, Rasa Baceviciene ${ }^{1}$, Tyler Vukmer ${ }^{1}$, Chante Karimkhani $^{3}$, Lindsay Boyers ${ }^{4}$, \\ Robert Dellavalle ${ }^{1,5,6}$ and Ryan Gamble ${ }^{*, 1}$
}

\author{
${ }^{I}$ Department of Dermatology, University of Colorado School of Medicine, Aurora, CO, USA \\ ${ }^{2}$ University of Arizona College of Medicine, Tucson, AZ, USA \\ ${ }^{3}$ Columbia University College of Physicians and Surgeons, New York, NY, USA \\ ${ }^{4}$ Georgetown University School of Medicine, Washington, D.C., USA \\ ${ }^{5}$ Department of Dermatology, Denver Veterans Affairs Medical Center, Denver, CO, USA \\ ${ }^{6}$ Department of Epidemiology, Colorado School of Public Health, Aurora, CO, USA
}

\begin{abstract}
Studies have established ultraviolet (UV) exposure with increased melanoma skin cancer risk. The combination of UV exposure, high altitude, and reflection of UV rays on the snow may create a particularly relevant and high-risk population amongst those who participate in snow sports. The current study aims to determine the effectiveness of a UV-photography and personalized counseling-based intervention to improve sun protection awareness on the snow sport enthusiast population. Participants were recruited at the 2013 SnowSports Industries American (SIA) Snow Show in Denver to complete a 14 question pre-survey assessing sun-safety awareness followed by a Faraghan Medical Elise Digital UV Camera photograph of their face and counseling regarding individual results. Participants were contacted one to two months later by telephone to complete a ten question post-survey. Forty-one percent of participants (46/112) completed both pre- and post-surveys. The UV photography based intervention influenced the opinions and behaviors of sun protection in $78 \%$ of male and $62 \%$ of female participants with sunscreen use identified as the most frequently modified behavior (53\%). While valid barriers to UV photography use include a current lack of reimbursement and lack of public knowledge of its utility, our study indicates the potential impact of UV photography-based interventions among high-risk populations who avidly participate in snow sports.
\end{abstract}

Keywords: Melanoma, snow sports, sun awareness, sun habits, sun protection, sunscreen, tanning, ultraviolet photography, ultraviolet radiation.

\section{INTRODUCTION}

Over the past decade, the rate of melanoma in the United States has increased approximately 2.6 percent each year, accounting for over 9,000 deaths in 2013 alone [1]. Sun exposure is a well-established risk factor for melanoma, along with fair skin type, positive family melanoma history, and genetic predisposition [2]. Prevention strategies include limiting sun exposure, using protective clothing and sunscreen, and avoidance of artificial ultraviolet (UV) exposure, such as indoor tanning beds [3]. Recent studies have employed UV photography as a personalized, imagebased tool that allows for patient interaction and discussion of potential sun exposure risks and counseling regarding sunprotection promotion [3-8]. Gibbons and Mahler et al. describe a reduction in college students' intention to tan, tanning behavior, and measured skin tan (using a colorimeter) when UV photography was employed $[5,8]$. These

*Address correspondence to this author at the University of Colorado, 1655 Aurora Ct, Mail Stop F703, ACP Rm 3233, CO, USA; Fax: (303) 393-4686; E-mail: ryan.gamble@ucdenver.edu findings suggest that a personalized, interactive approach, with emphasis on high-risk populations, may be an efficacious and valuable approach to skin cancer prevention and awareness.

The combination of high altitude and reflection of UV rays on the snow place those who participate in snow sports at significantly increased risk of excessive UV exposure. However, the impact of UV exposure and effective prevention strategies in this high-risk population are yet to be determined. The current study aims to determine the effectiveness of an intervention consisting of UV photography and personalized counseling encouraging sunsafe behavior to improve sun protection awareness and practices in this population.

\section{METHODS}

Participants were recruited at the 2013 SnowSports Industries America (SIA) Snow Show in Denver, Colorado from January 31 to February 3, 2013. Prior to getting their photo taken with the Faraghan Medical Elise Digital UV Camera, participants completed a 14 question survey 
Table 1. Pre-Photo Survey Results for 112 Participants

\begin{tabular}{|l|l|l|l|l|l|}
\hline Does snow magnify the intensity of sun exposure during skiing and snowboarding? \\
\hline & Definitely yes & Probably & Not sure & Probably not & N/A \\
\hline N $(\%)$ & $102(91)$ & $8(7)$ & $0(0)$ & $0(0)$ & $2(2)$ \\
\hline
\end{tabular}

How often do you wear a helmet or hat that shades your face, ears, and neck when skiing or snowboarding?

\begin{tabular}{|l|l|l|l|l|l}
\hline & Never & Rarely & Sometimes & Often & Always \\
\hline $\mathrm{N}(\%)$ & $12(11)$ & $13(11)$ & $12(11)$ & $27(24)$ & $48(43)$ \\
\hline
\end{tabular}

How often do you wear sunglasses or goggles when skiing or snowboarding?

\begin{tabular}{|l|l|l|l|l|l} 
& Never & Rarely & Sometimes & Often & Always \\
\hline $\mathrm{N}(\%)$ & $0(0)$ & $2(2)$ & $4(4)$ & $15(13)$ & $91(81)$ \\
\hline
\end{tabular}

If you wear sunglasses or goggles, do they have UV protective lenses?

\begin{tabular}{|l|l|l|l|l|l|l|}
\hline \multicolumn{2}{|l|}{} & Yes & No & Don't know & N/A & \\
\hline $\mathrm{N}(\%)$ & $94(84)$ & $2(2)$ & $15(13)$ & $1(1)$ & \\
\hline \\
How often do you wear sunscreen when skiing or snowboarding? \\
\hline $\mathrm{N}(\%)$ & Never & Rarely & Sometimes & Often & Always \\
\hline $7(6)$ & $13(12)$ & $33(30)$ & $24(21)$ & $35(31)$ \\
\hline
\end{tabular}

What is the sun protection factor of the sunscreen that you use most often?

\begin{tabular}{|l|l|l|l|l|l} 
& Less than 30 & 30 or greater & Don't know & Don't use & N/A \\
\hline $\mathrm{N}(\%)$ & $35(31)$ & $67(60)$ & $4(4)$ & $5(4)$ & $1(1)$ \\
\hline
\end{tabular}

Does your sunscreen have both UVA and UVB protection?

\begin{tabular}{|l|l|l|l|l|l|}
\hline & Yes & No & Don't know & Don't use & \\
\hline $\mathrm{N}(\%)$ & $52(46)$ & $1(1)$ & $56(50)$ & $3(3)$ & \\
\hline
\end{tabular}

How many times last ski season (winter 2011-2012) did you get a peeling burn?

\begin{tabular}{|l|l|l|l|l|l|}
\hline & 0 & 1 & 2 & $3-6$ & $>7$ \\
\hline $\mathrm{N}(\%)$ & $71(63)$ & $26(23)$ & $8(7)$ & $4(4)$ & $3(3)$ \\
\hline
\end{tabular}

How many times this ski season (winter 2012-2013) did you get a peeling burn?

\begin{tabular}{|l|l|l|l|l|l|l|}
\hline & 0 & 1 & 2 & $3-6$ & $>7$ \\
\hline $\mathrm{N}(\%)$ & $101(90)$ & $5(4)$ & $2(2)$ & $3(3)$ & $1(1)$ \\
\hline \multicolumn{5}{|l|}{ How many times in your life have you had a sunburn that blistered? } \\
\hline & 0 & $1-5$ & $6-10$ & $11-15$ & $>15$ \\
\hline $\mathrm{N}(\%)$ & $22(20)$ & $61(54)$ & $11(10)$ & $8(7)$ & $10(9)$ \\
\hline How would you describe your lifetime level of sun exposure? & Low-moderate & Moderate & High & Very High \\
\hline & Very low & $7(6)$ & $40(36)$ & $47(42)$ & $18(16)$ \\
\hline $\mathrm{N}(\%)$ & $0(0)$ & & \\
\hline
\end{tabular}

N/A- not applicable.

assessing their baseline sun safety awareness and behaviors. Each participant was shown their full-face frontal digital photograph highlighting UV-induced skin damage (Fig. 1) followed by sun safety recommendations. One to two months following the initial survey, a ten question follow-up survey was conducted via the phone to assess the impact of the UV photography-based intervention on sun safety practices during the winter 2012-2013 ski season. This study was approved by the Arizona Institutional Review Board, Protocol \#13-0037-00. Informed consent from the participants was obtained orally and participants were not compensated.

\section{RESULTS}

A total of 112 participants completed the initial presurvey. Of these, 46 participants $(41 \%)$ completed both the pre- and post-surveys. The demographics of the 46 participants demonstrated an average age of 37 (standard deviation 14) and gender distribution of $48 \%$ male and $51 \%$ female. According to the pre-survey, participants were more likely to always wear eye protection than a shading helmet or hat $(81 \%$ vs $42 \%$, respectively). Additionally, $58 \%$ of participants reported wearing sunscreen of $30 \mathrm{SPF}$ or greater, half of these did not know if their sunscreen provided both 


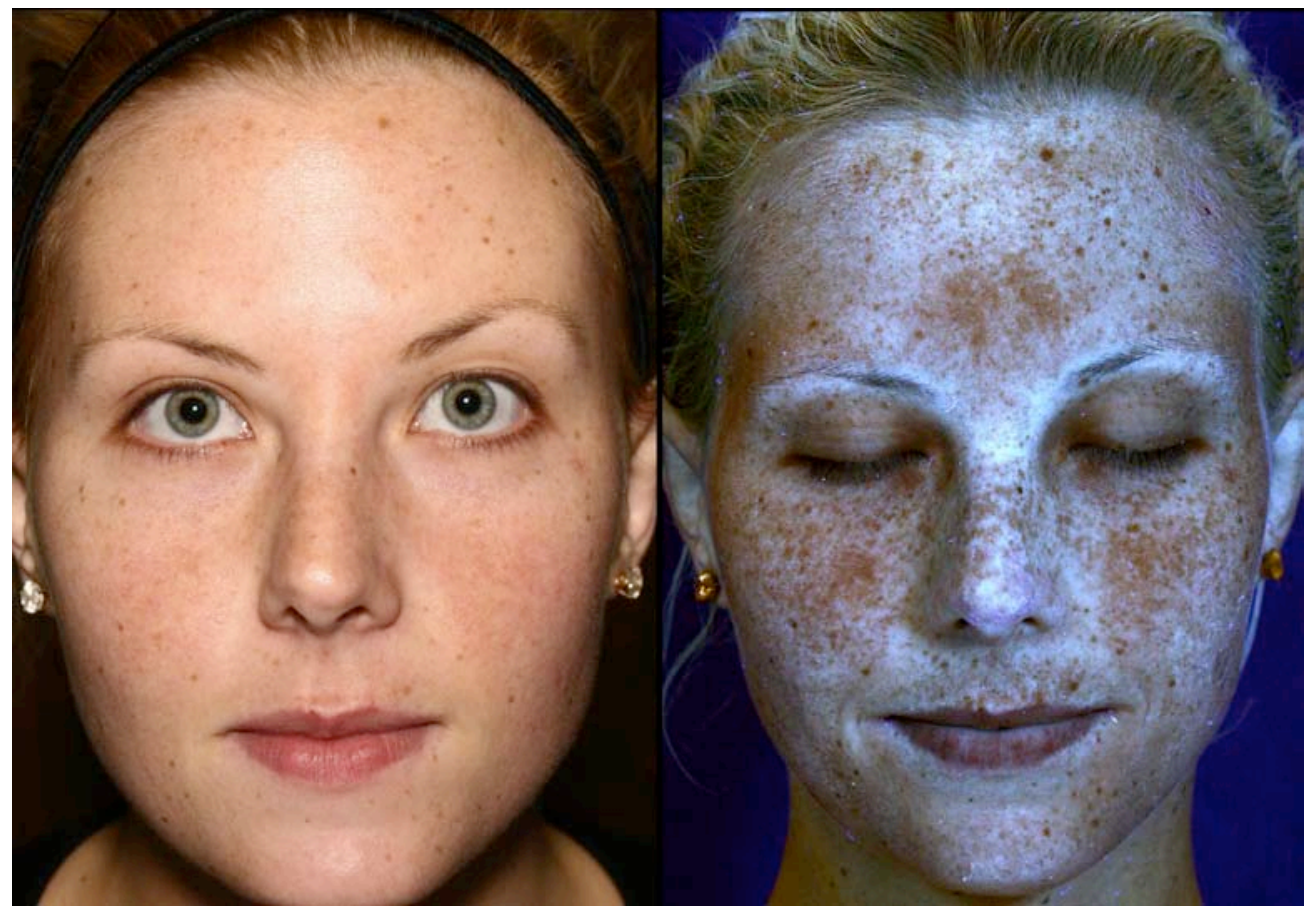

Fig. (1). Example of before UV camera exposure (left) compared to UV camera photo (right) highlighting UV damage. Image courtesy of Courtesty of Faraghan Medical Camera Systems.

\section{Table 2. Follow Up Survey Results for 46 Participants}

\begin{tabular}{|c|c|c|c|c|c|}
\hline \multicolumn{6}{|c|}{ Does snow magnify the intensity of sun exposure during skiing and snowboarding? } \\
\hline & Definitely yes & Probably & Not sure & Probably not & \\
\hline $\mathrm{N}(\%)$ & $44(96)$ & $2(4)$ & $0(0)$ & $0(0)$ & \\
\hline \multicolumn{6}{|c|}{ How many times last ski season (winter 2011-2012) did you get a peeling burn? } \\
\hline & 0 & 1 & 2 & $3-6$ & $>7$ \\
\hline $\mathrm{N}(\%)$ & $26(57)$ & $14(30)$ & $4(9)$ & $2(4)$ & 0 \\
\hline \multicolumn{6}{|c|}{ How many times this ski season (winter 2012-2013) did you get a peeling burn? } \\
\hline & 0 & 1 & 2 & $3-6$ & $>7$ \\
\hline $\mathrm{N}(\%)$ & $42(91)$ & $3(7)$ & $1(2)$ & 0 & 0 \\
\hline \multicolumn{6}{|c|}{ Did the UV camera photograph influence your opinion on sun protection? } \\
\hline & Yes & No & & & \\
\hline $\mathrm{N}(\%)$ & $35(78)$ & $10(22)$ & & & \\
\hline \multicolumn{6}{|c|}{ In what way(s) did the UV photograph influence your opinion on sun protection? } \\
\hline & Sun exposure & Sunscreen use & Hat/Helmet use & Sunglass/Goggle use & Other \\
\hline $\mathrm{N}(\%)$ & $16(36)$ & $24(53)$ & $6(13)$ & $4(9)$ & $5(11)$ \\
\hline \multicolumn{6}{|c|}{ Did the UV camera photograph influence your behavior on sun protection? } \\
\hline & Yes & No & & & \\
\hline $\mathrm{N}(\%)$ & $28(62)$ & $17(38)$ & & & \\
\hline \multicolumn{6}{|c|}{ In what way(s) did the UV photograph influence your behavior on sun protection? } \\
\hline & Sun exposure & Sunscreen use & Hat/Helmet use & Sunglass/Goggle use & Other \\
\hline $\mathrm{N}(\%)$ & $4(9)$ & $22(49)$ & $1(2)$ & $0(0)$ & $1(2)$ \\
\hline
\end{tabular}

UVA and UVB protection. The UV photography based intervention influenced the opinions and behaviors of sun protection in $78 \%$ of male and $62 \%$ of female participants
(Tables 1 and 2). The most frequently modified behavior was an increase in sunscreen use, which was observed in $53 \%$ of participants. 


\section{DISCUSSION}

Our study indicates the potential impact of UV photography-based interventions among high-risk populations who avidly participate in snow sports. We hypothesize that participants whose photographs appeared to show more severe photo damage would be likely to have a more significant immediate reaction to viewing their photograph, and a higher rate of sun-protective behavior response. Possible areas for future investigation include correlating the degree of sun damage in UV photographs with the extent of opinion and behavior change to determine whether this intervention has more impact on those with more sun damage and at higher risk. Barriers to the use of UV photography as a prevention strategy for melanoma include a current lack of reimbursement for providing this service and a lack of public knowledge of its utility. The current study was limited by the lack of assessment for individual participants' melanoma risk factors or skin type. A previous study by Gamble et al. demonstrated that the UV-photography intervention has a greater impact on individuals at higher risk for melanoma [7]. The poor followup response rate of $41 \%$ was likely impacted by conduction of the post-survey via phone. Future studies should consider electronic methods, such as online surveys delivered via email, as potentially more effective strategies to increase response rate. In addition, while the follow-up post-survey was performed one to two months later, further follow-up through the subsequent ski season would have allowed for assessment of the UV-based intervention's durable impact.

\section{CONFLICT OF INTEREST}

The authors confirm that this article content has no conflict of interest.

\section{ACKNOWLEDGEMENT}

Declared none.

\section{REFERENCES}

[1] National Cancer Institute. Surveillance, epidemiology, and end results programs: Turning cancer data into discovery. http://seer. cancer.gov/statfacts/html/melan.html [Accessed: February 2, 2014].

[2] Skin Cancer Foundation. Melanoma causes and risk factors. http:// www.skincancer.org/skin-cancer-

information/melanoma/melanoma-causes-and-risk-factors [Accessed February 2, 2014].

[3] Skin Cancer Foundation. Melanoma prevention guidelines. http://www.skincancer.org/skin-cancer-information/melanoma/mel anoma-prevention-guidelines [Accessed February 2, 2014].

[4] Mahler HI, Kulik JA, Gerrard M, Gibbons FX. Effects of upward and downward social comparison information on the efficacy of an appearance-based sun protection intervention: a randomized, controlled experiment. J Behav Med 2010; 33: 496-507.

[5] Mahler HI, Kulik JA, Gerrard M, Gibbons FX. Long-term effects of appearance-based interventions on sun protection behaviors. Health Psychol 2007; 26: 350-60.

[6] Mahler HI, Kulik JA, Harrell J, Correa A, Gibbons FX, Gerrard M. Effects of UV photographs, photoaging information, and use of sunless tanning lotion on sun protection behaviors. Arch Dermatol 2005; 141: 373-80.

[7] Gamble RG, Asdigian NL, Aalborg J, et al. Sun damage in ultraviolet photographs correlates with phenotypic melanoma risk factors in 12-year-old children. J Am Acad Dermatol 2012; 67(4): 587-97.

[8] Gibbons FX, Gerrard M, Lane DJ, Mahler HI, Kulik JA. Using UV photography to reduce use of tanning booths: a test of cognitive mediation. Health Psychol 2005; 24: 358-63. 